(2) Open Access Full Text Article

ORIGINAL RESEARCH

\title{
Examining Anxiety, Life Satisfaction, General Health, Stress and Coping Styles During COVID-19 Pandemic in Polish Sample of University Students
}

This article was published in the following Dove Press journal:

Psychology Research and Behavior Management

\section{Aleksandra M Rogowska (iD) Cezary Kuśnierz (iD ${ }^{2}$ Anna Bokszczanin (iD) \\ 'Institute of Psychology, University of Opole, Opole, Poland; ${ }^{2}$ Faculty of Physical Education and Physiotherapy, Opole University of Technology, Opole, Poland}

Purpose: The purpose of this study is to examine the association of anxiety with self-rated general health, satisfaction with life, stress and coping strategies of university students during the COVID-19 pandemic outbreak in Poland.

Participants and Methods: A total of 914 university students, ranged in age between 18 and 40 years old $(M=23.04, S D=2.60)$, participated in an online survey. The study was performed between 30 March and 30 April 2020, during the general coronavirus quarantine. Participants completed a standard psychological questionnaire, including General Anxiety Disorder (GAD-7), General Self-Rated Health (GSRH), Satisfaction With Life Scale (SWLS), Perceived Stress Scale (PSS), and Coping Inventory for Stressful Situations (CISS). Results: The majority of students $(65 \%)$ showed mild to severe GAD and a high level of perceived stress $(56 \%)$. Those students who had the worst evaluated current GSRH, in comparison to the situation before the COVID-19 outbreak, also demonstrated higher levels of anxiety, perceived stress, and emotion-oriented coping styles. The study indicates that the variance of anxiety during the COVID-19 outbreak may be explained for about $60 \%$ by such variables, like high stress, low general self-rated health, female gender, and frequent use of both emotion-oriented and task-oriented coping styles.

Conclusion: University students experience extremely high stress and anxiety during quarantine period and they need professional help to cope with COVID-19 pandemic. The results of this study may help prepare appropriate future intervention and effective prevention programs at universities.

Keywords: anxiety, COVID-19, coronavirus disease, perceived stress, physical health, satisfaction with life, styles of coping with stress, university students

\section{Introduction}

The coronavirus disease 2019 (COVID-19) is a highly infectious respiratory disease caused by severe acute respiratory syndrome-coronavirus-2 (SARS-Cov-2). ${ }^{1}$ The COVID-19 outbreak has rapidly extended globally from Wuhan (China) in early December of 2019. ${ }^{2}$ The first confirmed case of COVID-19 was noted on March 4, 2020, in Poland. The Polish government introduced a general state of the epidemic on March 20, 2020. As in other countries, also in Poland, the pandemic outbreak caused many restrictions in moving house, traveling, shopping, taking exercise, accessing critical public services including childcare or education, medical and
Correspondence: Aleksandra M Rogowska

Institute of Psychology, University of Opole, Plac Staszica I, Opole 45-052 Poland

Tel +48604732259

Email arogowska@uni.opole.pl 
social services, court, or victim support. Around 12,887 confirmed cases of COVID-19 had been reported in Poland, and 644 infected patients died from COVID-19 infection (ranged in age between 49 and 93 years old) between March 4 and April 30, 2020 (the last day of the present research). Among the Polish infected cases, 3236 patients have been recovered and discharged from different hospitals on April 30, 2020.

Quarantine of people who have potentially been exposed to a contagious disease is a form of struggling to slow down the transmission of the coronavirus disease. General quarantine requires people to restricting large gatherings, lockdown, and separate from friends and family. In the case of confirmed COVID-19, the total isolation from people who are not sick for a minimum of 14 days seems especially hard to bear. Maintain the limitation may be very difficult for many people. A recent review study ${ }^{3}$ showed that the adverse psychological effects of quarantine usually include confusion, anger, and post-traumatic stress symptoms, and also increase of the prevalence of anxiety and depressive symptoms in the general population. More prolonged quarantine duration increases stress related to infection fears, inadequate supplies, and support. The most common psychological and behavioral reactions on quarantine are irritability, nervousness, frustration, emotional disturbance, sadness, guilt, exhaustion, boredom, insomnia, inadequate information, poor concentration, and indecisiveness, detachment from others, deteriorating work performance, financial problems, and stigma.

The main changes in lifestyle and everyday habits are required to avoid infections, like washing hands frequently, use of face masks outside the home, avoidance of touching face, nose, eyes with hands, and social distancing. Unfortunately, this may have a significant impact on developing mental disorders. ${ }^{4}$ Ahorsu et $\mathrm{al}^{5}$ showed that the fear of COVID-19 positively correlates with depression, anxiety, perceived infectability, and germ aversion among Iranian people. When compared activity of Weibo (popular social media in China) users before and after the COVID-19 outbreak in China, Li et $\mathrm{al}^{6}$ found an increase in negative emotions, such as anxiety, depression, and indignation, and also a higher sensitivity to social risks. A decrease in positive emotions and life satisfaction was also noted.

Research conducted in China during the COVID-19 pandemic found lower levels of mental health alongside a higher rate of anxiety, depression, and alcohol use, than usual ratio. ${ }^{7}$ Many studies confirmed that around one-third of the Chinese population suffered from various forms of depression and anxiety (from mild to severe) related to lockdown at home during coronavirus pandemic outbreak, and also one-third of people have reported lower mental wellbeing. ${ }^{7-13}$ Research suggests that the female gender and may be related to lower satisfaction with life and higher stress and anxiety. ${ }^{11,13}$ Young adults (aged between 21 and 40 years) presented a higher risk of mental health disorders and alcohol use than the other parts of the population..$^{7-9}$ Moreover, the association of the severity of COVID-19 with satisfaction with life may depend on current health and exercise status. ${ }^{13}$

Research indicates that physical activity brings many health benefits such as improving cardiovascular and respiratory efficiency, the immune system by increasing the body's resistance to illness, a musculoskeletal system with body posture, and also the nervous system by supporting intellectual performance, reducing nervous tension as well as depressive and anxiety states, improving sleep quality and wellbeing. ${ }^{14-17}$ In the current lifestyle, physical fitness is treated as a means to achieve a better quality of life. Mohamed and Alawna ${ }^{16}$ showed that the aerobic capacity related to maintaining moderate to high levels of physical activity might prevent coronavirus disease and its severity. World Health Organization (WHO) prepared the campaign "Be Active during COVID-19", with recommendations about the weekly level of physical activity that can be achieved with limited space at home, and without any special equipment. ${ }^{18}$ However, Zhang et $\mathrm{al}^{13}$ showed that life satisfaction was negatively related to hours of exercise, which seem to suggest that physically active people might be more susceptible to poorer wellbeing during the quarantine. More research is necessary to explain this ambiguity.

Undergraduate students are very rarely a subject of interest for researchers, ${ }^{3}$ although psychological distress among them represents a significant health concern. ${ }^{19}$ In a recent study, Cao et $\mathrm{al}^{20}$ found that almost one-quarter of 7143 Chinese students reported symptoms of mild $(21.3 \%)$, moderate $(2.7 \%)$, and severe anxiety $(0.9 \%)$ during the COVID-19 pandemic outbreak.

This study aims to examine and explain the anxiety of Polish university students, with regards to the general health status during the COVID-19 pandemic outbreak, perceived stress, coping styles, gender, and faculty of undergraduates. For this purpose, we formulated the following research questions: 1) What is the prevalence of 
anxiety, stress, general health, and satisfaction with life in Polish students during the COVID-19 pandemic outbreak?; 2) Are there differences between students in gender and faculty, with regards to anxiety, perceived stress, general health, life satisfaction, and coping with stress? 3) When compared to the situation before the COVID-19 outbreak, is the current health status related to anxiety, perceived stress, general health, life satisfaction, and coping with stress, and coping with stress? 4) What is the association of anxiety during COVID-19 pandemic with gender, study faculty, self-rated general health, stress, satisfaction with life, and coping styles?

The following hypotheses were formulated: 1) According to previous research conducted in China during coronavirus pandemic, we hypothesize that university students will report lower levels of general health and satisfaction with life, as well as higher levels of stress than usual ratio; and also we assume that around one-third of the undergraduates will suffer from an anxiety disorder. ${ }^{7-}$ 13,20 2) We expect that the female gender is positively related to stress and anxiety and negatively related to life satisfaction. $^{11,13}$ Consistent with most of the previous research, that physical activity improves mental health, we expect that students of physical education faculty will report better indices of wellbeing than their peers from engineering faculty. ${ }^{14-17} 3$ ) As shown previously, we assume that the worst health status perceived during coronavirus pandemic is related to higher anxiety and stress, lower life satisfaction, and rare use coping styles. ${ }^{5-9,13,20-}$ 23 4) Finally, we hypothesize that heightened anxiety is associated positively with female gender, engineering faculty, perceived stress, and emotional coping style, while negatively with good health, satisfaction with life, and task-oriented coping. ${ }^{5-9}, 13,20-23$ A relationship of anxiety with general health status, satisfaction with life, perceived stress, and coping styles during general coronavirus quarantine will also be examined using both correlation and hierarchical regression analysis. The results of this study may help prepare appropriate future intervention and effective prevention programs at universities.

\section{Participants and Methods Study Design}

The study was performed between March 30 and April 30, 2020, during the highest level of general quarantine restrictions in Poland, related to the COVID-19 pandemic outbreak. The research was conducted using an online survey that included standardized psychological questionnaires and a few demographic questions about age, gender, and studying details. The invitation to participate in the study, with the link to survey form, was disseminated by the advertisement loaded on the e-learning platform (Moodle). E-learning platform was solely a device used by the whole University population for educational purposes during the COVID-19 pandemic outbreak, so all students had to see this information. The first page of the survey included information about research and invitation to participate by mark an informed consent. If the student not agreed, the survey was finished after this initial stage. The survey was usually completed in 20 minutes. Age between 18 and 40 years old was the only one eligibility criterium.

Initially, data collection included 986 people, but 12 students $(1.22 \%$ of the total sample) did not agree to the examination, and they were excluded at the initial stage from the study. Farther, 60 individuals $(6.09 \%$ of the total sample) were excluded from further statistical analysis because of missing data. The final data set consisted of 914 people, with a $100 \%$ response rate. The online form of informed consent was received from all individual participants involved in the study. The participants willingly and voluntarily participated in the research. The IRB approval of the University of Opole was obtained for the study design and data collection. All procedures performed in studies involving human participants were in accordance with the ethical standards of the institutional research committee, the APA ethical standards, and the 1964 Helsinki Declaration and its later amendments or comparable ethical standards.

\section{Participants}

Participants in the study were 914 students from the Opole University of Technology (OUT) in the South of Poland, Europe, ranged in age $18-40$ years old $(M=23.04, S D=$ $2.60)$, with the prevalence of men ( $n=520,56.89 \%)$. Students represented all university faculties at various levels of higher education. Table 1 demonstrates the details of demographic characteristics in the total sample, in order to age, gender, faculty, and level, year, and type of study. For further statistical analysis, the total sample was grouped regarding gender (394 women and 520 men) and faculty (350 students of Physical Education and Physiotherapy faculty, and 564 students of engineering faculties). The total number of students at the OUT is 5847, including 4070 of full-time students, and 1777 of 
Table I Demographic Characteristics of the Sample

\begin{tabular}{|l|l|l|}
\hline Demographic Variables & $\mathbf{n}$ & $\%$ \\
\hline Age & 23.04 & 2.60 \\
\hline Gender & 394 & 43.11 \\
\hline Women & 520 & 56.89 \\
\hline Men & \multicolumn{2}{|l|}{} \\
\hline Faculty & 350 & 38.29 \\
\hline Physical Education and Physiotherapy & 64 & 7.00 \\
Economics and Management & 88 & 9.52 \\
Production Engineering and Logistics & 31 & 3.39 \\
Civil Engineering and Architecture & 94 & 10.28 \\
Mechanical & 5 & 0.55 \\
Technical Systems Engineering & 282 & 30.85 \\
Electrical Engineering. Automation and Computer & \multicolumn{2}{|l}{} \\
Science & 759 & 83.04 \\
\hline Level of study & 155 & 16.96 \\
\hline First degree (undergraduate. engineering. BA) & 566 & 61.93 \\
Secondary degree (master. MA) & 242 & 26.48 \\
Master degree five-years study (MA) & 98 & 10.72 \\
Third degree (doctoral) & 8 & 0.88 \\
\hline Year of study & 2308 & 33.70 \\
\hline First & 236.49 & 25.82 \\
Second & 72 & 7.88 \\
Third & 65 & 7.11 \\
\hline Fourth & \multicolumn{2}{|l}{} \\
\hline Fifth & \multicolumn{2}{|l}{} \\
\hline Full-time studies & \multicolumn{2}{|l}{} \\
\hline
\end{tabular}

extramural. The present study sample accounts for $15.63 \%$ of the total number of students. We assume that a sample of Physical Education and Physiotherapy (PEP) students will differ in physical activity (PA) when compared to students from engineering (ENG) faculty. The rationale of this assumption is that PEP students took significantly more classes with PA during study at University than ENG students. Students of all engineering fields have a total of 30 hours of PA classes per only one semester (2 hours weakly) during the whole course of study. They may choose the type of physical activity according to their interests among team sports (football, handball, volleyball, basketball), and individual sports (eg, fitness, self-defense, aerobics, table tennis, strength exercises). PE students have an average of 10 hours of PA classes each week each semester and each year of study. Besides the forms of PA mentioned above, PE students may also choose a sport discipline among swimming and athletics. Moreover, PE students must complete one summer camp of 60 hours (with swimming, sailing, and windsurfing) and one winter camp (45 hours of skiing, downhill skiing, and snowboarding) during the first-degree study.

\section{Measures}

\section{Anxiety}

Generalized Anxiety Disorder (GAD-7) was developed by Spitzer et $\mathrm{al}^{24}$ as a brief clinical measure for assessing anxiety severity. The GAD-7 is a 7-item self-report measure designed to screen for symptoms following DSM-IV criteria. Participants rated on a 4-point Likert scale $(0=$ Not at all, $1=$ Several days, $2=$ More than half the days, and 3 = Nearly every day) how often they experienced anxiety symptoms in the past 2 weeks. Total scores range from 0 to 21, with a cut-off value for identifying cases of GAD at 10 points. Scores ranging $0-4$ indicating no or minimal anxiety, between 5 and 9 mild, between 10 and 14 moderate, and between 15 and 21 severe GAD. In this study, the Cronbach's $\alpha$ for the GAD-7 was 0.92.

\section{General Health}

General Self-Rated Health (GSRH) status was measured here to assess health-related quality of life. Two singleitem of the GSRH questions were developed by DeSalvo et $\mathrm{al}^{25}$ as a shorter alternative of standard general health survey (SF-12V). The first question (GSRH-1) "In general, would you say your health is ...?" was rated on the 5-point Likert scale, with options: 1 = Excellent, 2 = Very Good, 3 = Good, $4=$ Fair, and $5=$ Poor. The same scale of response was used in the second question (GSRH -2) "Compared to others your age, would you say your health is ...?". Research indicates that poorly self-rated health in the singleitem GSRH has a strong association with mortality. ${ }^{26}$ The third question was developed here on the base of GSRH-1. The participant was asked to assess his/her health concerning the COVID-19 (Coronavirus-Related General SelfRated Health, CRGSRH-1): "Before the quarantine, your state of health was ... ". The response scale was the same as described above in the GSRH-1 and GSRH-2. The last question (CRGSRH-2) was as follows: "Compared to the situation before quarantine, your health is now ..." was rated on the 5 -point scale $(1=$ Much better, $2=$ Better, $3=$ Same, $4=$ Worse, $5=$ Much worse). In the present study, the 
reliability coefficient (Cronbach's $\alpha$ ) for original GSRH equals 0.85 , and.79 for all four items.

\section{Life Satisfaction}

Satisfaction With Life Scale (SWLS) is a 5-item scale developed by Diener et $\mathrm{al}^{27}$ to measure global cognitive judgments of one's life satisfaction. Participants indicate how much they agree or disagree with each of the five items using a 7 -point scale (from $1=$ Strongly disagree to $7=$ Strongly agree). Total scores range from 5 to 35 , with higher scores indicating a higher level of life satisfaction. The ranges of scores may be interpreted as Extremely dissatisfied (5-9), Dissatisfied (10-14), Slightly dissatisfied (15-19), Neutral (20), Slightly satisfied (21-25), Satisfied (26-30), and Extremely satisfied (31-35). The Cronbach's $\alpha$ for the SWLS in the present sample is 0.84 .

\section{Stress}

Perceived Stress Scale (PSS) is one of the most frequently use a self-report instrument for measuring psychological stress is one of the more popular tools for measuring psychological stress. ${ }^{28}$ Individuals rate on a 5-point Likert scale (ranging from $0=$ Never, to $4=$ Very often), how often during the previous month their life has been seen as unpredictable, uncontrollable, and overloaded. Total scores range between 0 and 40, with higher scores indicating higher levels of perceived stress. The extremely low level of perceived stress may be considered when scores ranging between 5 and 11, low level if ranging 12-17, average level if they are between 18 and 23, high level from 24 to 28 , and extremely high between 29 and 35 . The internal consistency of the PSS-10, measured in the present study by Cronbach's $\alpha$ coefficient, equals 0.87 .

\section{Coping Styles}

Coping Inventory for Stressful Situations (CISS) was derived from both theoretical and empirical bases and developed by Endler and Parker ${ }^{29}$ as a self-report measure of responses to stressful circumstances. The 48-item CISS measure individual style of coping with stress on three dimensions (16 items in each dimension), including taskoriented, emotion-oriented, and avoidance-oriented coping styles. Task-oriented coping style aimed at cognitively restructuring and solving the problem attempts to alter the situation, focusing on task and planning. Emotionoriented coping style describes self-oriented emotional reactions in stressful situations (eg, self-blaming, getting angry, upset, becoming tense, self-preoccupation, and fantasizing), aimed to reduce stress. Coping with avoiding stress is designed to alleviate stress through activities such as distractions by other situations or tasks or social gatherings. Respondents are asked to rate on a 5-point Likert scale (ranging from $1=$ Not at all, to $5=$ Very much) the degree of engagement in various types of activity during a difficult, stressful, or upsetting situation. Scores for 16 items per each of three scales are summed, with higher scores interpreted as a higher level of the particular coping style. Internal consistency scores in the present study are good for task, emotion, and avoidanceoriented coping, with Cronbach's a coefficients: 0.91, 0.78 , and 91 , respectively.

\section{Statistical Analysis}

Descriptive statistics, such as mean $(M)$, standard deviation $(S D)$, range, standard error $(S E)$, and $95 \%$ confidential interval $(C I)$ with lower limit $(L L)$ and upper limit $(U L)$, was conducted for the total sample at the beginning. Then, a series of two-way ANOVA was performed to examine gender and faculty differences in general health, satisfaction with life, anxiety disorder, perceived stress, and coping styles. Next, a series of one-way ANOVA was conducted to examine differences in life satisfaction, anxiety, stress and coping styles, between students that self-rated current health status related to the situation before coronavirus COVID-19 outbreak, as ranged between $1=$ Much better and $5=$ Much worst. The effect size was measured by partial eta-squared $\left(\eta_{p}{ }^{2}\right)$, which describes the ratio of variance explained in the dependent variable by a predictor in the model of ANOVA. The relationship between variables was examined using Pearson's correlation analysis and hierarchical regression analysis. The perceived stress was an explained (dependent) variable in three subsequent models. In the first step, two demographic variables (gender and faculty) were included in the model. The second model also included wellbeing measures (general self-rated health, satisfaction with life, and general anxiety disorders), beside demographics. The third model consisted of demographic variables, wellbeing measures, and three styles of coping with stress (task-, emotion-, and avoidance-oriented).

\section{Results}

\section{Prevalence of Anxiety, Stress, Health and Satisfaction with Life Among Students}

Descriptive statistics and psychometric properties of variables are presented in Table 2. Prevalence of GAD was high, with $65 \%$ of students suffered from anxiety, including 
Table 2 Descriptive Statistics in the Total Sample $(N=9 \mid 4)$

\begin{tabular}{|c|c|c|c|c|c|c|}
\hline \multirow[b]{2}{*}{ Variables } & \multirow[b]{2}{*}{ Range } & \multirow[b]{2}{*}{$M$} & \multirow[b]{2}{*}{$S D$} & \multirow[b]{2}{*}{$S E$} & \multicolumn{2}{|c|}{$95 \% \mathrm{Cl}$} \\
\hline & & & & & LL & UL \\
\hline $\begin{array}{l}\text { Health - current } \\
\text { status (CS) }\end{array}$ & $\mathrm{I}-5$ & 2.38 & 0.82 & 0.03 & 2.33 & 2.44 \\
\hline $\begin{array}{l}\text { Health - } \\
\text { compared to } \\
\text { others }\end{array}$ & $1-5$ & 2.48 & 0.92 & 0.03 & 2.42 & 2.54 \\
\hline $\begin{array}{l}\text { Health - before } \\
\text { quarantine (BQ) }\end{array}$ & $\mathrm{I}-5$ & 2.26 & 0.79 & 0.03 & 2.21 & 2.32 \\
\hline $\begin{array}{l}\text { Health - in } \\
\text { comparison } \mathrm{CS} \\
\text { and } \mathrm{BQ}\end{array}$ & $\mathrm{I}-5$ & 3.09 & 0.67 & 0.02 & 3.05 & 3.13 \\
\hline $\begin{array}{l}\text { Satisfaction with } \\
\text { life }\end{array}$ & $5-35$ & 21.97 & 5.86 & 0.19 & 21.59 & 22.35 \\
\hline $\begin{array}{l}\text { General anxiety } \\
\text { disorder }\end{array}$ & $0-21$ & 7.85 & 5.59 & 0.18 & 7.48 & 8.21 \\
\hline Perceived stress & $0-40$ & 20.32 & 8.38 & 0.28 & 19.78 & 20.87 \\
\hline $\begin{array}{l}\text { Task-oriented } \\
\text { coping style }\end{array}$ & $16-80$ & 52.48 & 10.78 & 0.36 & 51.78 & 53.18 \\
\hline $\begin{array}{l}\text { Emotion- } \\
\text { oriented coping } \\
\text { style }\end{array}$ & $16-80$ & 40.65 & 12.86 & 0.43 & 39.82 & 41.48 \\
\hline $\begin{array}{l}\text { Avoidance- } \\
\text { oriented coping } \\
\text { style }\end{array}$ & $16-80$ & 43.89 & 9.44 & 0.31 & 43.27 & 44.50 \\
\hline
\end{tabular}

$32 \%$ of mild $(n=297), 21 \%$ of moderate $(n=192)$, and $14 \%$ cases of severe anxiety disorder $(n=124)$. Extremely low level of perceived stress have $2 \%$ of the sample $(n=15)$, low level present 22\% ( $n=197)$, average 21\% $(n=188)$, high $31 \%(n=285)$ and extremely high $25 \%(n=229)$. Most of students rated their general health as very good $(n=404$, $44 \%)$, good $(n=336,37 \%)$, and excellent $(n=115,13 \%)$, and only $6 \%$ feel not well ( $5 \%$ of fair health status, $n=48$; $1 \%$ of poor health, $n=11)$. Majority of students are satisfied with their life from slightly to extremely ( $n=569,63 \%$ of total sample), only $5 \%$ of participants have neutral attitude to satisfaction with life $(n=50)$, and $32 \%$ are dissatisfy with life from slightly to extremely $(n=295)$.

\section{Gender and Faculty Differences}

The results of two-way ANOVA for gender (Men, Women) and faculty (PEP, ENG) as a factor, and general health, coronavirus-related health, satisfaction with life, anxiety disorder, perceived stress, and coping styles as a dependent variable, is demonstrated in Table 3. Women scored significantly higher than men in all three scales of general health, anxiety, perceived stress, and emotion and avoidance styles of coping with stress. The PEP sample scored lower than ENG students in the GSRH-2, CSSRH-1, GAD, and PSS, and they have higher scores in the SWLS and Avoidance scale of the CISS. However, it is important to note that the effect size in the ANOVA analyses is very small and ranges from 0.01 to 0.04 .

\section{Impact of Coronavirus-Related General Health on Anxiety, Stress, Life Satisfaction and Coping Styles}

A series of one-way ANOVA was performer separately for satisfaction with life, perceived stress, anxiety disorder, and three coping styles: task-oriented, emotionoriented, and avoidance-oriented. Independent variable was the scale derived from answer to the question about relations of current health status in comparison to situation before coronavirus COVID-19 outbreak. The total sample was divided into five groups due to answer for the CRGSRH-2 scale as $1=$ Much better $(n=24), 2=$ Better $(n=73), 3=$ Same $(n=636), 4=$ Worst $(n=$ $159)$, and $5=$ Much worst $(n=22)$. Figure 1 shows the mean scores in satisfaction with life, perceived stress, general anxiety disorder, and coping styles, in a particular group rating their coronavirus-related general health in comparison to the situation before quarantine. The scores of each dependent variable in the total sample were converted to the standardized Z-scores prior to analysis, to show the relative differences between the clusters. The values for each variable at the zero mean may be classified as average level, below the zero mean indicate lower level, and the values above the zero mean indicate a higher level of the variable. The significant differences were found for satisfaction with life $\left[F(4,909)=7.43, p<0.001, \eta_{p}{ }^{2}\right.$ $=0.03]$, perceived stress $[F(4,909)=30.41, p<0.001$, $\left.\eta_{p}{ }^{2}=0.12\right]$, general anxiety disorder $[F(4,909)=37.77$, $\left.p<0.001, \eta_{\mathrm{p}}{ }^{2}=0.14\right]$, emotion-oriented coping style $[F$ $\left.(4,909)=22.44, p<0.001, \eta_{p}{ }^{2}=0.09\right]$, and avoidanceoriented coping style $\left[F(4,909)=5.26, p<0.001, \eta_{p}{ }^{2}=\right.$ 0.02]. Not significant effect of ANOVA was noted in task-oriented coping style $[F(4,909)=0.72, p=0.576$, $\left.\eta_{p}^{2}=0.00\right]$. 
Table 3 Means, Standard Deviations, and Two-Way ANOVA Statistics for Study Variables

\begin{tabular}{|c|c|c|c|c|c|c|}
\hline & \multicolumn{2}{|c|}{ Women } & \multicolumn{2}{|c|}{ Men } & \multirow[b]{2}{*}{$F(1910)$} & \multirow[b]{2}{*}{$\eta_{p}{ }^{2}$} \\
\hline Variables & $M$ & $S D$ & $M$ & $S D$ & & \\
\hline Health - current status (CS) & 2.44 & 0.77 & 2.34 & 0.85 & $5.28 *$ & 0.01 \\
\hline Health - compared to others & 2.52 & 0.89 & 2.46 & 0.95 & $4.77^{*}$ & 0.01 \\
\hline Health - before quarantine (BQ) & 2.26 & 0.74 & 2.27 & 0.83 & 0.81 & 0.00 \\
\hline Health - in comparison CS and BQ & 3.14 & 0.65 & 3.05 & 0.68 & $4.70^{*}$ & 0.01 \\
\hline Satisfaction with life & 22.61 & 5.51 & 21.49 & 6.08 & 2.59 & 0.00 \\
\hline General anxiety disorder & 8.86 & 5.40 & 7.08 & 5.61 & $30.29 * * *$ & 0.03 \\
\hline Perceived stress & 21.64 & 8.00 & 19.33 & 8.53 & $24.5 I^{* * *}$ & 0.03 \\
\hline Task-oriented coping style & 52.33 & 9.87 & 52.60 & 11.43 & 0.29 & 0.00 \\
\hline Emotion-oriented coping style & 42.63 & 13.13 & 39.15 & 12.46 & $17.97 * * *$ & 0.02 \\
\hline \multirow[t]{2}{*}{ Avoidance-oriented coping style } & 46.67 & 8.59 & 41.78 & 9.52 & $35.78 * * *$ & 0.04 \\
\hline & \multicolumn{2}{|c|}{ PEP } & \multicolumn{2}{|c|}{ ENG } & & \\
\hline Variables & $M$ & $S D$ & $M$ & $S D$ & $F(1910)$ & $\eta_{p}^{2}$ \\
\hline Health - current status (CS) & 2.35 & 0.75 & 2.40 & 0.86 & 2.56 & 0.00 \\
\hline Health - compared to others & 2.35 & 0.82 & 2.56 & 0.97 & $13.76 * * *$ & 0.01 \\
\hline Health - before quarantine (BQ) & 2.19 & 0.71 & 2.31 & 0.83 & $5.79 * *$ & 0.01 \\
\hline Health - in comparison CS and $B Q$ & 3.09 & 0.65 & 3.09 & 0.68 & 0.63 & 0.00 \\
\hline Satisfaction with life & 22.80 & 5.52 & 21.46 & 6.02 & $7.06 * *$ & 0.01 \\
\hline General anxiety disorder & 7.53 & 5.35 & 8.04 & 5.72 & $8.11 * *$ & 0.01 \\
\hline Perceived stress & 19.72 & 7.79 & 20.70 & 8.71 & $9.27 * *$ & 0.01 \\
\hline Task-oriented coping style & 52.56 & 9.99 & 52.44 & 11.26 & 0.07 & 0.00 \\
\hline Emotion-oriented coping style & 40.60 & 12.96 & 40.68 & 12.81 & 1.68 & 0.00 \\
\hline Avoidance-oriented coping style & 46.84 & 9.01 & 42.05 & 9.24 & $33.3 I^{* * *}$ & 0.04 \\
\hline
\end{tabular}

Notes: $*_{p}<0.05, *_{p}<0.01$, $* * p<0.001$.

\section{Explaining Anxiety Levels During Coronavirus Quarantine}

The correlation analysis was performed to examine the association between all variables. As it is shown in Table 4, task-oriented coping style is not related to anxiety and emotion-oriented coping, and avoidance coping style is not related to life satisfaction and coronavirus-related general health. The other variables correlate with each other at a high level of significance $(p<$ $0.001)$. Hierarchical regression analysis was performed in three steps to examine the association of anxiety with demographic dimensions (gender and faculty), and general self-rated health, satisfaction with life, perceived stress and three coping styles: task-oriented, emotionoriented, and avoidance-oriented. The first model included two demographic variables: sex and faculty. Results of the regression analysis showed that both variables are significant predictors of anxiety, but they explain variance of dependent variable for about $3 \%, \mathrm{R}^{2}$
$=0.03, \mathrm{R}_{\text {adj. }}^{2}=0.03, \mathrm{~F}(2,911)=15.80, p<0.001$. The second model of regression included both demographic variables and also perceived stress, self-rated general health, and life satisfaction. The percent of variance explained raised in the second step to $54 \%$, $R^{2}=0.55, R_{\text {adj. }}^{2}=0.54, F(5,908)=217.70, p<$ 0.001 . Among independent variables included in the model, all variables were found as significant predictors of anxiety disorders, except faculty and satisfaction with life. The third model of regression included variables from the second step and also three dimensions of coping style. This model explained for about $60 \%$ of total variance, $R^{2}=0.61, R_{\text {adj. }}^{2}=0.60, F(8,905)=175.23$, $p<0.001$. Significant and positive predictors of anxiety disorders were such variables as perceived stress, general health, and both task-oriented and emotion-oriented coping styles. Faculty, satisfaction with life, and avoidance coping style were not found as a significant predictors of anxiety. More details are shown in Table 5. 


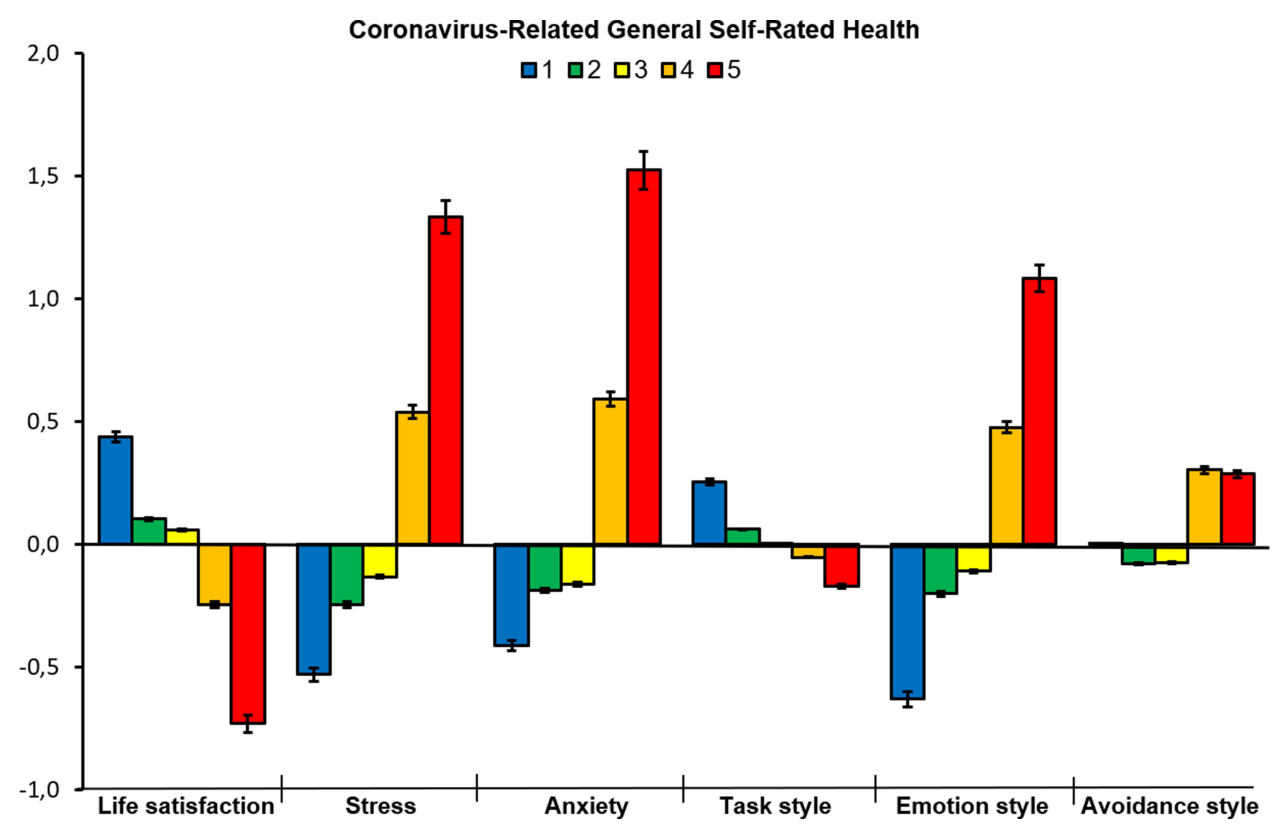

Figure I Mean values of standardized Z-scores for satisfaction with life, perceived stress, general anxiety disorder, task-, emotion-, and avoidance-oriented coping,styles in a five groups of students representing self-rated current health status in comparison to the situation before coronavirus COVID-I9 outbreak, as ranged between I = Much better to $5=$ Much worst. Error bars represent $95 \% \mathrm{Cl}$.

\section{Discussion}

Prevalence of Anxiety, Stress, Health and Satisfaction with Life in the Sample of Polish Students During Coronavirus Pandemic Outbreak

This study examined anxiety with regard to perceived stress, general health, and satisfaction of life among university students during the COVID-19 pandemic outbreak in Poland. We have expected that Polish students will experience lower levels of general health and satisfaction with life, and higher levels of stress and anxiety, than usual ratio, similar to the Chinese population. ${ }^{7-13,20}$ Contrary to assumptions, the study results indicate that majority of students (94\%) well-rated their health (as excellent, very good, or good). Also, there was an overall average level of satisfaction with life in the study sample, which is inconsistent with our hypothesis. The majority of Polish students demonstrate a high level of anxiety $(65 \%$ have mild to severe GAD) and a high level of perceived stress (56\% have high or extremely high scores). It must be noted that the prevalence of anxiety and high stress among Polish students is much higher than in previous studies conducted in China during the COVID-19 outbreak. ${ }^{6-11,20,30}$

For instance, an online survey study found the $22.6 \%$ prevalence of anxiety, among the general population of Chinese citizens of Wuhan (China), during COVID-19 outbreak. ${ }^{30}$ Huang and $\mathrm{Zhao}^{9}$ suggest that the prevalence of GAD in the Chinese population is $35 \%$ during the COVID-19 pandemic outbreak. As it was evidenced by

Table 4 Correlation Matrix Between All Variables

\begin{tabular}{|c|c|c|c|c|c|c|c|c|}
\hline \multicolumn{2}{|c|}{ Variables } & I. & 2. & 3. & 4. & 5. & 6. & 7. \\
\hline I. & Perceived stress & & & & & & & \\
\hline 2. & Satisfaction with life & $-.49 * * *$ & & & & & & \\
\hline 3. & Health - current status & $0.44 * * *$ & $-.37 * * *$ & & & & & \\
\hline 4. & Health - before quarantine & $0.27^{* * *}$ & $-.30 * * *$ & $0.69 * * *$ & & & & \\
\hline 5. & General anxiety disorder & $0.73^{* * *}$ & $-.35 * * *$ & $0.41 * * *$ & $0.20 * * *$ & & & \\
\hline 6. & Task-oriented coping style & $-.24 * * *$ & $0.24 * * *$ & $-.19 * * *$ & $-.17 * * *$ & -.06 & & \\
\hline 7. & Emotion-oriented coping style & $0.64 * * *$ & $-.40 * * *$ & $0.38 * * *$ & $0.24 * * *$ & $0.66 * * *$ & -.01 & \\
\hline 8. & Avoidance-oriented coping style & $0.18^{* * * *}$ & 0.00 & $0.09 * *$ & -.03 & $0.21 * * *$ & $0.17^{* * * *}$ & $0.38 * * *$ \\
\hline
\end{tabular}

Notes: $* * p<0.01, * * * p<0.001$. 
Table 5 Hierarchical Regression Results for Perceived Stress

\begin{tabular}{|c|c|c|c|c|c|c|c|c|}
\hline & & & 95\% & pr $b$ & & & & \\
\hline \multicolumn{2}{|c|}{ Variables } & $\boldsymbol{b}$ & $L L$ & UL & $S E b$ & $\boldsymbol{\beta}$ & $R^{2}$ & $R_{\text {adj. }}^{2}$ \\
\hline \multicolumn{2}{|l|}{ Step I } & & & & & & 0.03 & $0.03 * * *$ \\
\hline & Constant & $22.61 * * *$ & 21.58 & 23.64 & 0.52 & & & \\
\hline & Gender & $-2.81 * * *$ & -3.94 & -1.68 & 0.58 & $-0.17 * * *$ & & \\
\hline & Faculty & $-1.79 * *$ & -2.94 & -0.64 & 0.59 & $-0.10 * *$ & & \\
\hline \multicolumn{2}{|l|}{ Step 2} & & & & & & 0.61 & $0.60 * * *$ \\
\hline & Constant & $19.84 * * *$ & 17.53 & 22.14 & 1.17 & & & \\
\hline & Gender & $-1.14 * *$ & -1.88 & -0.40 & 0.38 & $-0.07^{* *}$ & & \\
\hline & Faculty & -0.31 & -1.05 & 0.42 & 0.38 & -0.02 & & \\
\hline & Health - current status & $0.99 * * *$ & 0.51 & 1.46 & 0.24 & $0.10 * * *$ & & \\
\hline & Satisfaction with life & $-0.36 * * *$ & -0.43 & -0.30 & 0.03 & $-0.26 * * *$ & & \\
\hline & General anxiety disorder & $0.88 * * *$ & 0.81 & 0.95 & 0.04 & $0.59 * * *$ & & \\
\hline \multicolumn{2}{|l|}{ Step 3} & & & & & & 0.65 & $0.65 * * *$ \\
\hline & Constant & $19.68 * * *$ & 16.71 & 22.65 & 1.51 & & & \\
\hline & Gender & $-0.83^{*}$ & -1.54 & -0.12 & 0.36 & $-0.05^{*}$ & & \\
\hline & Faculty & -0.50 & -1.22 & 0.21 & 0.36 & -0.03 & & \\
\hline & Health - current status & $0.58^{*}$ & 0.12 & 1.04 & 0.23 & $0.06 *$ & & \\
\hline & Satisfaction with life & $-0.26 * * *$ & -0.32 & -0.19 & 0.03 & $-0.18 * * *$ & & \\
\hline & General anxiety disorder & $0.7 I^{* * *}$ & 0.63 & 0.79 & 0.04 & $0.47^{* * *}$ & & \\
\hline & Task-oriented coping style & $-0.12 * * *$ & -0.15 & -0.09 & 0.02 & $-0.16 * * *$ & & \\
\hline & Emotion-oriented coping style & $0.15^{* * *}$ & 0.11 & 0.18 & 0.02 & $0.22 * * *$ & & \\
\hline & Avoidance-oriented coping style & 0.01 & -0.03 & 0.05 & 0.02 & 0.01 & & \\
\hline
\end{tabular}

Notes: Gender was coded: Women $=0$, Men $=1$; Faculty was coded: ENG $=0$, PEP $=1 . * p<0.05, * * p<0.01, * * * p<0.001$.

Liang et $\mathrm{al}^{22}$ nearly $40 \%$ of the Chinese individuals were found to be prone to psychological problems just two weeks after the coronavirus outbreak. Zhang and $\mathrm{Ma}^{23}$ showed that Chinese respondents reported mild stressful impact of COVID-19 outbreak (only $7.6 \%$ of participants experienced moderate to severe stress impact) in the study. A review of the existing literature suggests that the most common psychological reactions to the COVID-19 pandemic are symptoms of anxiety and depression (16-28\%) and self-reported stress $(8 \%){ }^{23}$

Firstly, differences exist between particular Chinese studies in prevalence stress and anxiety. It may be dependent on the stage of COVID-19 pandemic development. Secondly, various measurements used to assessing stress and anxiety might affect the outcome. Böckerman et $\mathrm{al}^{31}$ showed that two health-related quality-of-life measures could not capture the negative effects of some chronic conditions (among self-reported somatic conditions and four psychiatric disorders) on subjective wellbeing in the Finnish population. On the other hand, university students in Poland had higher scores in psychological distress compared to students from the UK and Germany in past research. ${ }^{19}$ It was suggested that the reasons were related to financial and job market problems. Marek et $\mathrm{al}^{32}$ noticed a high level of anxiety among $29 \%$ of medical students.

The other explanation of the inconsistency between Chinese and Polish study results may be related to crosscultural differences. Chinese is a collective society, whereas Polish is individualistic. Lack of controllability caused by COVID-19 may be perceived as more dangerous among people from individualistic countries, like Poland. On the other hand, collectivist society can give more support to its members. $\mathrm{Li}$ et $\mathrm{al}^{6}$ found that Chinese people were more concerned about health and family during the COVID-19 pandemic outbreak and less concern for leisure and friends. Zhang and $\mathrm{Ma}^{23}$ showed that their Chinese respondents reported increasing support from close relatives and friends, and increasing shared feeling and caring with family members. That 
protective buffer in the Chinese population may play a key role in controlling stress and anxiety during the pandemic. However, because the support from family and friends was not examined in the present study, future research should assess this question in the Polish students.

There may be several reasons to experience increased anxiety during the general quarantine of a coronavirus in the student's population. The majority of Polish students work and studying concurrently. ${ }^{33}$ For many students, their gainful employment is the only source of income during their studies. In Poland, income from work among university students is a more substantial component than the European average (40\%), while all other parts, such as family contribution (46\%), public support (11\%) and others (3\%), are slightly smaller. ${ }^{34}$ During the COVID-19 outbreak and a general quarantine, most of the students had to leave the dorms and the university city and go to their family homes. The vast majority of students lost their jobs - the primary source of income. Similarly, the risk of losing a job appeared in their parents (who also contribute significantly to maintenance during their studies). The entire labor market collapsed, so araises concerns about finding a job in the future after graduation. The disruption of educational activities due to a cancellation of the traditional model of person-to-person educational didactics, lectures, and chalk talks, can have a negative impact on academic achievement. ${ }^{35,36}$ A sudden change in the education system with closed educational institutions, and the implementation of large-scale, long-distance web-based teaching in a virtual learning platform, have proved to be very difficult for many students and lecturers, which is additional sources of stress. ${ }^{37,38}$ Many students from rural areas reported unavailability or poor internet connection, which has an impact on complete their tasks at virtual educational platforms. Prolonged isolation and social distancing, loss of contact with lecturers, and lack of support from classmates, and concerns about the postponement of examinations, lead to increased fear of passing the semester. Many university students feel lost in the new situation related to coronavirus quarantine.

Also, perceived state support and a high level of uncertainty may have an impact on the levels of stress and anxiety. The situation during the COVID-19 pandemic outbreak is difficult in Poland. Trust in the state is very poor. ${ }^{39}$ The medical service has various problems for many years, and current support is usually inappropriate. The number of coronavirus tests is too small (much smaller than in other countries). The public information is a subject of propaganda, the low regulation is insufficient in the pandemic state, and support of the governments is very weak or none at all. All of these problems may generate more reason for assessing the higher perception of risk related to the COVID-19 outbreak, which, in consequence, may lead to increase stress and anxiety. More research is needed from various countries, to fully explain the disparities in prevalence stress and anxiety during coronavirus quarantine.

\section{Gender Differences in the Wellbeing Indices of University Students}

In the present study, significantly worst indices of mental health demonstrate female students than males in such self-rated dimensions as physical health, anxiety, and stress. This result is consistent with the study of Wang et $\mathrm{al}^{11}$ in which female gender and poor self-rated health status were significantly associated with a higher level of stress, anxiety, and also with a higher perceived impact of the outbreak on the individual's life. Also, the first nationwide, large-scale survey study showed that psychological distress is significantly higher in the female population of China during the COVID-19 epidemic, in comparison to males. ${ }^{40}$ However, the other studies conducted in China during the COVID-19 pandemic outbreak did not found gender differences in mental health. Gender had no significant effect on anxiety among medical college students, ${ }^{20}$ as well as among the general population. ${ }^{9}$ Also, Zhang and $\mathrm{Ma}^{23}$ did not found gender differences in the stressful impact of the COVID-19 outbreak. This inconsistency may be related to cross-cultural differences.

On the other hand, most of the research on mental disorders indicates that women scored higher in anxiety than men, which is consistent with our findings. ${ }^{41}$ Worry about health, social relationship, work and socioeconomic status, and directly about the future, may increase during coronavirus pandemic quarantine. In the metaanalytic review, Olatunji et $\mathrm{al}^{41}$ demonstrated a greater severity and frequency of worry in patients with an anxiety disorder (GAD), than among nonpsychiatric controls. Worry may also help explain gender differences, with higher stress, and anxiety among women. According to biological explanations, women are more vulnerable to maladaptive rumination and worry during the premenstrual period, the postpartum period, and 
menopause, which is determined by hormonal fluctuations. Conversely, gender differences in anxiety may be explained, using differences in coping style. Women tended to more frequently use an emotion-oriented and avoidance-oriented coping styles when compared to men.

\section{Faculty Differences the Wellbeing Among University Students}

Faculty also may have an impact on the mental health of university students. Similar to other studies, evidence of this study indicates that there is a positive effect of PA on wellbeing during coronavirus pandemic outbreak among University students. ${ }^{14-17}$ The sample of physical education faculty showed significantly better general health (lower scores), lower level of anxiety and perceived stress, and also higher levels of life satisfaction than their peers from engineering faculty. It may suggest that the PEP students are much better at dealing with the difficult situation caused by the coronavirus quarantine, that ENG group. Our research is consistent with growing evidence in the scientific literature that physical activity (in particular aerobic exercises, such as running or cycling) modulates hormones, amino acids, and neurotransmitters levels, decreasing psychological stress and alleviating depression and anxiety. ${ }^{15}$ Recent research indicates that an active lifestyle with an appropriate level of exercise and healthy dietary habits can affect immune aging positively. ${ }^{17}$ Maintaining a high level of physical activity with age may improve many features of immunosenescence. ${ }^{14}$ A recent review showed that increasing the aerobic capacity could improve immune competence, which fulfills the protective role against COVID-19, decreasing its severity. ${ }^{16}$ The mechanism of improving immunity based on 1) increasing the function of immune cells and immunoglobulins regulating CRP levels and lead to decrease anxiety and depression; 2) improving the respiratory system and restoring lung tissue elasticity and strength; 3 ) decreasing COVID-19 risk factors.

However, Zhang et $\mathrm{al}^{13}$ showed that satisfaction with life is negatively associated with hours of exercise among working adults in China one month into the COVID-19 outbreak. Those individuals who exercised a lot (above 2.5 hours per day) were less satisfied than suggests that they might be more frustrated by the restrictions due to the outbreak. First of all, everyday physical training lasting more than 2.5 hours may be very aggravating and indicate rather an exercise addiction, which is related to insomnia and also dissatisfaction, irritation, and fear if the routine is changed. Most of the people do physical exercise outside the home, in beautiful surroundings among nature or with other people in the fitness club, gym hall, or playground. A diverse environment and meetings with a team of players are as important (or even more) as physical activity. Home-based physical training can be limited and boring, and thus may increase frustration and angry.

\section{Impact of Coronavirus-Related Health on Anxiety, Stress, General Health, and Satisfaction with Life}

A high level of stress and anxiety may be interpreted as a consequence of fear for health during the COVID-19 pandemic outbreak, as it was evidenced in ANOVA outcomes in this study. The most significant differences were found between groups that feel much better during coronavirus quarantine, and those that rated their general health as much worst now in comparison to situation before COVID-19 outbreak, regards anxiety (effect size was $\eta_{\mathrm{p}}{ }^{2}$ $=0.14$ ), perceived stress (effect size was $\eta_{\mathrm{p}}{ }^{2}=0.12$ ), and emotion-oriented coping style (effect size was $\eta_{\mathrm{p}}{ }^{2}=0.09$ ). The other group's differences in life satisfaction and avoidance coping style are significant at $p$-value $<0.001$ but may have marginal importance since effect size are very poor $\left(\eta_{\mathrm{p}}{ }^{2}\right.$ was between 0.01 and 0.03$)$. Those of university students, who felt the worst, also experienced anxiety and stress highly, and frequently use emotionoriented coping, which is related to discharge of negative emotions such as anger, irritation, frustration, or sadness. This result is consistent with previous research. ${ }^{5-9,13,20-23}$ Hao et $\mathrm{al}^{21}$ showed that individuals with poor or worse physical health status during the COVID-19 pandemic outbreak also scored significantly higher in anxiety, and stress. Dar et $\mathrm{al}^{42}$ showed that stressful situations could increase anxiety.

\section{Relationship of Anxiety with Health, Life Satisfaction, Stress, and Coping Styles, During Coronavirus Quarantine}

This study aimed to explain anxiety during the general coronavirus quarantine. The result of correlation analysis suggests that a high level of anxiety is related to higher stress, worst health, lower levels of satisfaction with life, and more frequent using emotional-oriented and avoidance-oriented coping styles. A task-oriented coping style is not correlated with anxiety. The relationship between 
anxiety, physical health, satisfaction with life, perceived stress, and coping styles, found in this study, is consistent with previous research. ${ }^{5-9,13,20-23}$

For the first time, we had performed multiple hierarchical regression analysis to explain the specific relationship of anxiety with perceived stress, general physical health, satisfaction with life, and three styles of coping with stress (task-, emotion-, and avoidance-oriented), when such confounding as gender and faculty were under control. The full model of hierarchical regression analysis accounted for $54 \%$ of the variance and indicated that the most important for anxiety are following variables: perceived stress, physical health, emotion-oriented coping, task-oriented coping, and gender (women rated their stress at higher levels than men). Interestingly, the task-oriented coping style is related positively with anxiety in this model of regression. Some research indicates that anxiety is negatively associated with problem-focused coping, and changing perspective, while positively with searching support, emotion-focused and avoidance coping. ${ }^{42-44}$ On the other hand, Kasi et $\mathrm{al}^{45}$ found that such problem-focused coping strategies as acceptance, use of instrumental support, and active coping, were most commonly used in patients with an anxiety disorder. It seems possible that people who most often use a task-oriented style of coping with a stressful situation, effectively reduce the level of stress (as shown in this study) while increasing the level of anxiety. Increased anxiety appears to be associated with the unpredictable COVID-19 pandemic situation, with extremely high uncertainty about the future. Taskoriented coping styles may be useless and instead increase the level of frustration when people cannot perform tasks and create plans for the future due to quarantine restrictions.

There are several recommendation to cope with the coronavirus outbreak. We suggest that University students need to be more engaged in physical activity, even more than usual. Systematic physical activity at the level of physical recreation may help to reduce stress and anxiety, as well as to maintain physical fitness, body efficiency, and proper body weight.

Home-based physical training is recommended during coronavirus quarantine. ${ }^{17,46}$

Geldsetzer ${ }^{47}$ performer an online survey to determine knowledge and perceptions of coronavirus disease among the general public in the United States and the United Kingdom. Although most of the participants reported good knowledge of the common symptoms and transmission of COVID-19, a misconception concerns about how to prevent infection and the recommended careseeking behavior. The findings indicate the critical role of media, clinicians, and public health authorities, who should modeling behavior and provide information campaigns to reduce misperceptions during the COVID-19 outbreak.

Chaturvedi ${ }^{4}$ postulates that the main protective strategies during the COVID-19 outbreak should be focused on training of social skills, encouraging social interactions, and reducing social distances. Because of limited activities which individuals can engage at home, Chaturvedi ${ }^{4}$ suggests enhancing the use of mobile phones or the internet and mainly using social media.

However, Gao et $\mathrm{al}^{30}$ showed that mental health problems (anxiety and depression) are positively associated with frequent social media exposure during the COVID-19 outbreak. Thus, we recommended our students to the use of social media with caution. Brinkman ${ }^{48}$ suggests some strategies focused on increasing awareness of how to manage anxieties and fears and effectively cope with the COVID-19 virus. Saleh et $\mathrm{al}^{49}$ showed significant improvements in coping with stress, and greater satisfaction with studies among college students, after applying the online self-help program based on cognitive-behavioral therapy, and composed just of four sessions.

Also, Hiremath et $\mathrm{al}^{50}$ formulated several tips to overcome the impact of COVID-19 on mental health, including anxiety, panic, and fear, loneliness, difficulty in concentrating, low motivation and a state of distraction, negative emotional spirals, desperation, financial strain, and apprehension about future. To reduce mental stress threshold, Hiremath et $\mathrm{al}^{50}$ suggest to prioritize physical and mental health, sleep thoroughly, eat healthy food, exercise regularly, and to include meditation to an everyday routine. Liu et $\mathrm{al}^{51}$ proved the efficacy of progressive muscle relaxation in reducing anxiety and improving sleep quality during COVID-19.

The students with diagnosed mental problems, such as depression or anxiety disorder, should be under constant control of psychological and psychiatric services. Hao et $\mathrm{al}^{21}$ examined physical and psychiatric symptoms among psychiatric patients as compared to healthy control subjects from Chongqing (China). The mean scores in stress, and anxiety, were significantly higher in psychiatric patients than healthy controls. Also, psychiatric patients demonstrated higher levels of anger, impulsivity, severe worries about their physical health, and more intense suicidal ideation, when compared to healthy 
controls. Hu et $\mathrm{al}^{52}$ emphasize the role and need for the development of online mental services to help maintain the support of mentally ill patients during the COVID-19 pandemic.

\section{Limitation of the Study}

There is some limitation of this study. Although the sample size in the present study is large and representative for technical university, the results of this study may not be generalized to the whole population of university students in Poland as well as in other countries. More research is necessary to compare the wellbeing of university students around the world. Future research should include students from various types of universities (private and national) and faculties (eg, medical, social sciences, or technical). The research concerns the beginning of the general coronavirus quarantine, when the level of stress and anxiety may be the highest. It is possible that over time and the acquisition of competence in dealing with the coronavirus quarantine, stress and anxiety would be gradually reduced. Future research should be performed prospectively at various stages of coronavirus spread. The response rate could contribute to a biased sample in the present study. It is possible, that those students who feel overall well did not participate in the research, whereas those who experience higher discomfort during the COVID-19 pandemic, were more likely to share their negative emotions trough survey form. Thus stress and anxiety may be overestimated here due to fear related to the coronavirus outbreak. On the other hand, psychiatric disorders were not under control in this study, so mean levels of anxiety and stress in this study could be heightened by the participation of people with a past history of anxiety, depression, or posttraumatic stress disorder. In future studies, cases of people with mental disorders should be excluded from the analysis. Finally, this study did not control for such variables related to anxiety and stress as contact with family, habitat (alone vs with family), time spent on social media sites. Further research should include these covariates in examining anxiety and stress during COVID-19 among university students.

\section{Conclusion}

The main conclusion of this research is that university students experience very high anxiety and stress during the COVID-19 pandemic and they need support and guideline to better manage stress and fear in this unusual situation. Fortunately, the university seems an excellent environment to implement protective strategies focused on preventing mental disorders as well as psychological intervention and treatment. The results of the study suggest that students need more competences to cope with coronavirusrelated stress. First of all, a higher risk of negative consequences of coronavirus outbreak on wellbeing regards female students and those of engineering faculty.

We may conclude that if students worry too much about their health, the level of stress may increase, which may be an additional source of anxiety. Simultaneously, students should use to the less extend emotion-oriented coping to reduce anxiety, which is related to such strategies of coping as self-focused emotional reactions towards stress, such as blame, angry, tense, daydreaming, selfpreoccupation. In particular, task-oriented coping, focusing on resolve problems, troubleshooting, seeking relevant information, and try to changing or eliminating the source of stress, seems ineffective because of uncontrollable and unpredictable coronavirus pandemic. University should implement intervention programs to prevent mental health disorders during COVID-19 quarantine. On the other hand, university students could choose some of the recommended strategies to improve their skills to cope with stress and anxiety during coronavirus pandemic.

\section{Acknowledgment}

This research was financially supported by the Opole University of Technology.

\section{Disclosure}

The authors report no conflicts of interest in this work.

\section{References}

1. Kakodkar P, Kaka N, Baig MN. A comprehensive literature review on the clinical presentation, and management of the pandemic coronavirus disease 2019 (COVID-19). Cureus. 2020;12(4):e7560. doi: $10.7759 /$ cureus. 7560

2. Baloch S, Baloch MA, Zheng T, Pei X. The coronavirus disease 2019 (COVID-19) pandemic. Tohoku J Exp Med. 2020;250(4):271-278. doi:10.1620/tjem.250.271

3. Brooks SK, Webster RK, Smith LE, et al. The psychological impact of quarantine and how to reduce it: a rapid review of the evidence. Lancet. 2020;395:912-920. doi:10.1016/S0140-6736(20)30460-8

4. Chaturvedi SK. C COVID -19, coronavirus, and mental health rehabilitation at times of crisis. J Psychosoc Rehabil Ment Health. 2020;7:1-2.

5. Ahorsu DK, Lin CY, Imani V, Saffari M, Griffiths MD, Pakpour AH. The fear of COVID-19 scale: development and initial validation. Int J Ment Health Addict. 2020;1-9. doi:10.1007/s11469-020-00270-8

6. Li S, Wang Y, Xue J, Zhao N, Zhu T. The impact of COVID-19 epidemic declaration on psychological consequences: a study on active Weibo users. Int J Environ Res Public Health. 2020;17(6):2032. doi:10.3390/ijerph17062032 
7. Ahmed Z, Ahmed O, Aibao Z, Hanbin S, Siyu L, Ahmad A. Epidemic of COVID -19 in china and associated psychological problems. Asian J Psychiatr. 2020;51:102092. doi:10.1016/j. ajp.2020.102092

8. Huang Y, Zhao N. Chinese mental health burden during the COVID-19 pandemic. Asian $J$ Psychiatr. 2020;51:102052. doi:10.1016/j.ajp.2020.102052

9. Huang Y, Zhao N. Generalized anxiety disorder, depressive symptoms and sleep quality during COVID-19 outbreak in China: a web-based cross-sectional survey. Psychiatry Res. 2020;288:112954. doi:10.1016/j.psychres.2020.112954

10. Rajkumar RP. Covid-19 and mental health: a review of the existing literature. Asian $J$ Psychiatr. 2020;52:102066. doi:10.1016/j. ajp.2020.102066

11. Wang C, Pan R, Wan X, et al. Immediate psychological responses and associated factors during the initial stage of the 2019 coronavirus disease (COVID-19) epidemic among the general population in China. Int $J$ Environ Res Public Health. 2020;17(5):1729. doi:10.3390/ijerph17051729

12. Wang C, Pan R, Wan X, et al. A longitudinal study on the mental health of general population during the COVID-19 epidemic in China. Brain Behav Immun. 2020;87:40-48. doi:10.1016/j. bbi.2020.04.028

13. Zhang SX, Wang Y, Rauch A, et al. Unprecedented disruption of lives and work: health, distress and life satisfaction of working adults in china one month into the COVID-19 outbreak. Psychiatr Res. 2020;288:112958. doi:10.1016/j.psychres.2020.112958

14. Duggal NA, Pollock RD, Lazarus NR, Harridge S, Lord JM. Major features of immunesenescence, including reduced thymic output, are ameliorated by high levels of physical activity in adulthood. Aging Cell. 2018;17(2):e12750. doi:10.1111/acel.12750

15. Heijnen S, Hommel B, Kibele A, Colzato LS. Neuromodulation of aerobic exercise-a review. Front Psychol. 2016;6:1890. doi:10.3389/ fpsyg. 2015.01890

16. Mohamed AA, Alawna M. Role of increasing the aerobic capacity on improving the function of immune and respiratory systems in patients with coronavirus (COVID-19): a review. Diabetes Metab Syndr. 2020;14(4):489-496. doi:10.1016/j.dsx.2020.04.038

17. Weyh C, Krüger K, Strasser B. Physical activity and diet shape the immune system during aging. Nutrients. 2020;12(3):622. doi: $10.3390 /$ nu 12030622

18. World Health Organization. Be active during COVID-19. [homepage on the Internet]; 2020. Available from: https://www.who.int/emergen cies/diseases/novel-coronavirus-2019/question-and-answers-hub /q-a-detail/be-active-during-covid-19. Accessed June 5, 2020.

19. Essau CA, O'Callaghan J, Ederer E, Bokszczanin A, Sasagawa S. Depressive, anxiety, and stress symptoms among young people from three european countries. In: Głębocka A, Gawor A, editors. Quality of Life - Different Perspectives. Kraków, Poland: Oficyna Wydawnicza Impuls; 2008:105-113.

20. Cao W, Fang Z, Hou G, et al. The psychological impact of the COVID-19 epidemic on college students in China. Psychiatry Res. 2020;287:112934. doi:10.1016/j.psychres.2020.112934

21. Hao F, Tan W, Jiang L, et al. Do psychiatric patients experience more psychiatric symptoms during COVID-19 pandemic and lockdown? A case-control study with service and research implications for immunopsychiatry. Brain Behav Immun. 2020;87:100-106. doi:10.1016/j.bbi.2020.04.069

22. Liang L, Ren H, Cao R, et al. The effect of COVID-19 on youth mental health. Psychiatr Q. 2020;1-12. doi:10.1007/s11126-02009744-3.

23. Zhang Y, Ma ZF. Impact of the COVID-19 pandemic on mental health and quality of life among local residents in Liaoning Province, China: a cross-sectional study. Int J Environ Res Public Health. 2020;17(7):2381. doi:10.3390/ijerph17072381
24. Spitzer RL, Kroenke K, Williams JBW, Löwe B. A brief measure for assessing generalized anxiety disorder: the GAD-7. Arch Intern Med. 2006;166(10):1092-1097. doi:10.1001/archinte.166.10.1092

25. DeSalvo KB, Fisher WP, Tran K, Bloser N, Merrill W, Peabody J. Assessing measurement properties of two single-item general health measures. Qual Life Res. 2006;15(2):191-201. doi:10.1007/s11136005-0887-2

26. DeSalvo KB, Fan VS, McDonell MB, Fihn SD. Predicting mortality and healthcare utilization with a single question. Health Serv Res. 2005;40(4):1234-1246. doi:10.1111/j.1475-6773.2005.00404.x

27. Diener E, Emmons RA, Larsen R, Griffin S. The satisfaction with life scale. J Pers Assess. 1985;49:71-75. doi:10.1207/s15327752jpa4901 13

28. Cohen S, Kamarck T, Mermelstein R. A global measure of perceived stress. J Health Soc Behav. 1983;24(4):385-396. doi:10.2307/ 2136404

29. Endler NS, Parker JD. Multidimensional assessment of coping: a critical evaluation. J Pers Soc Psychol. 1990;58(5):844-854. doi:10.1037//0022-3514.58.5.844

30. Gao J, Zheng P, Jia Y, et al. Mental health problems and social media exposure during COVID-19 outbreak. PLoS One. 2020;15(4): e0231924. doi:10.1371/journal.pone.0231924

31. Böckerman P, Johansson E, Saarni SI. Do established health-related quality-of-life measures adequately capture the impact of chronic conditions on subjective wellbeing? Health Policy. 2011;100:91-95. doi:10.1016/j.healthpol.2010.10.008

32. Marek K, Białoń P, Wichowicz H, Melloch H, Nitka-Siemińska A. Screening trial for frequency of depressive and anxiety symptoms among students of Medical University of Gdańsk. Psychiatria. 2005;2(4):2171-2224.

33. Główny Urząd Statystyczny [Central Statistical Office]. Oświecenie i edukacja w roku szkolnym 2018/2019 [Education and upbringing in the school year 2018/2019]; 2019. Available from: https://stat.gov.pl/ obszary-tematyczne/edukacja/edukacja/oswiata-i-wychowaniew-roku-szkolnym-20182019,1,14.html. Accessed June 5, 2020.

34. Hauschildt K, Gwosć C, Netz N, Mishra S Social and economic conditions of student life in Europe. Synopsis of indicators EUROSTUDENT V 2012-2015. Available from: https://www.euro student.eu/download_files/documents/EVSynopsisofIndicators.pdf. Accessed June 5, $20 \overline{2} 0$.

35. Almarzooq ZI, Lopes M, Kochar A. Virtual learning during the COVID-19 pandemic: a disruptive technology in graduate medical education. J Am Coll Cardiol. 2020;75(20):2635-2638. doi:10.1016/ j.jacc.2020.04.015

36. Daniel SJ. Education and the COVID-19 pandemic. Prospects. 2020. doi:10.1007/s11125-020-09464-3

37. Zhang X. Thoughts on large-scale long-distance web-based teaching in colleges and universities under novel coronavirus pneumonia epidemic: a case of chengdu university. Proc. 4th ICCESE; 13-14 March 2020, Moscow, Russia; 1222-1225. https://doi.org/10.2991/assehr.k. 200316.266

38. Gautam R, Sharma M. 2019-nCoV pandemic: a disruptive and stressful atmosphere for Indian academic fraternity. Brain Behav Immun. 2020;S0889-1591(20):30506-30507. doi:10.1016/j.bbi.2020.04.025

39. Młokosiewicz M, Misiak-Kwit S. The impact of trust on entrepreneurship in Poland. JEMI. 2017;13(4):79-95. doi:10.7341/20171345

40. Qiu J, Shen B, Zhao M, Wang Z, Xie B, Xu Y. A nationwide survey of psychological distress among Chinese people in the COVID-19 epidemic: implications and policy recommendations. Gen Psychiatry. 2020;33:19-21. doi:10.1136/gpsych-2020-100213

41. Olatunji BO, Wolitzky-Taylor KB, Sawchukc CN, Ciesielski BG. Worry and the anxiety disorders: a meta-analytic synthesis of specificity to GAD. Appl Prev Psychol. 2010;14:1-24. doi:10.1016/j. appsy.2011.03.001

42. Dar KA, Iqbal N, Mushtaq A. Intolerance of uncertainty, depression, and anxiety: examining the indirect and moderating effects of worry. Asian J Psychiatr. 2017;29:129-133. doi:10.1016/j.ajp.2017.04.017 
43. Whatley SL, Foreman AC, Richards S. The relationship of coping style to dysphoria, anxiety, and anger. Psychol Rep. 1998;83 (3):783-791. doi:10.2466/pr0.1998.83.3.783

44. Kasi PM, Naqvi HA, Afghan AK, et al. Coping styles in patients with anxiety and depression. ISRN Psychiatry. 2012;2012:128672. doi: $10.5402 / 2012 / 128672$

45. Pozzi G, Frustaci A, Tedeschi D, et al. Coping strategies in a sample of anxiety patients: factorial analysis and associations with psychopathology. Brain Behav. 2015;5(8):e00351. doi:10.1002/ brb3.351

46. Hammami A, Harrabi B, Mohr M, Krustrup P. Physical activity and coronavirus disease 2019 (COVID-19): specific recommendations for home-based physical training. Manag Sport Leis. 2020;1-6. doi: $10.1080 / 23750472.2020 .1757494$

47. Geldsetzer P. Use of rapid online surveys to assess people's perceptions during infectious disease outbreaks: a cross-sectional survey on
COVID-19. J Med Internet Res. 2020;22(4):e18790. doi:10.2196/ 18790

48. Brinkman A. Coping with the COVID-19 virus. Kai Tiaki Nurs N Z. 2020;26(3):25.

49. Saleh D, Camart N, Sbeira F, Romo L, van Wouwe JP. Can we learn to manage stress? A randomized controlled trial carried out on university students. PLoS One. 2018;13(9):e0200997. doi:10.1371/journal.pone.0200997

50. Hiremath P, Suhas Kowshik CS, Manjunath M, Shettar M. COVID 19: impact of lock-down on mental health and tips to overcome. Asian J Psychiatr. 2020;51:102088. doi:10.1016/j.ajp.2020.102088

51. Liu K, Chen Y, Wu D, et al. Effects of progressive muscle relaxation on anxiety and sleep quality in patients with COVID-19. Complement Ther Clin Pract. 2020;39:101132. doi:10.1016/j.ctcp.2020.101132

52. Hu N, Pan S, Sun J, Wang Z, Mao H. Mental health treatment online during the COVID-19 outbreak. Eur Arch Psychiatry Clin Neurosci. 2020;1-2. doi:10.1007/s00406-020-01129-8

\section{Publish your work in this journal}

Psychology Research and Behavior Management is an international, peer-reviewed, open access journal focusing on the science of psychology and its application in behavior management to develop improved outcomes in the clinical, educational, sports and business arenas. Specific topics covered in the journal include: Neuroscience, memory and decision making; Behavior modification and management; Clinical applications; Business and sports performance management; Social and developmental studies; Animal studies. The manuscript management system is completely online and includes a very quick and fair peer-review system, which is all easy to use. Visit http://www. dovepress.com/testimonials.php to read real quotes from published authors. 